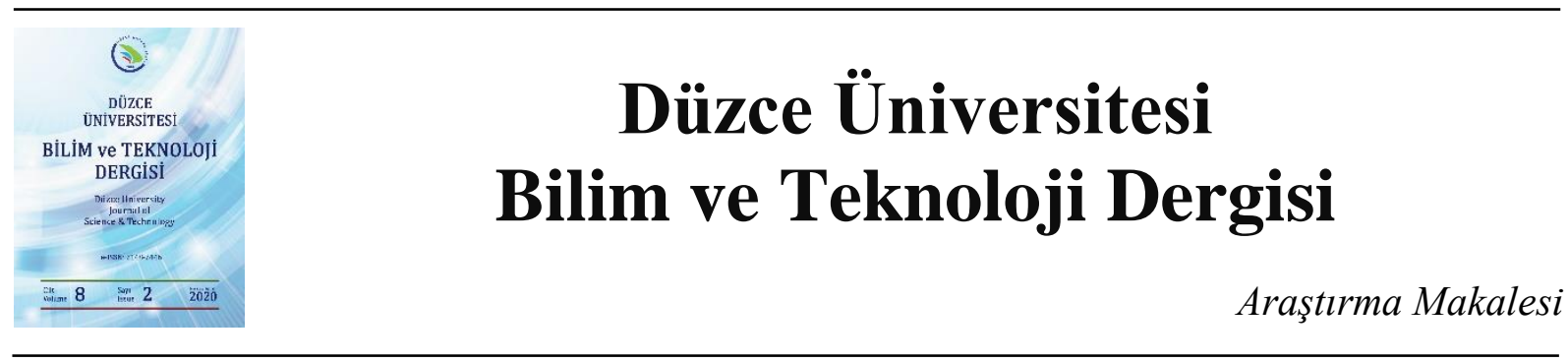

\section{Türkiye 400 KV’luk Güç Sistemi İçin Optimal Fazör Ölçüm Birimlerinin Yerleşim Yerlerinin Belirlenmesi}

\author{
Beytullah BOZALİ ${ }^{\text {a }}$, (iD Ali ÖZTÜRK ${ }^{\text {b }}$ \\ ${ }^{a}$ Elektrik ve Enerji Bölümü, Düzce MYO, Düzce Üniversitesi, Düzce, TÜRKIYYE \\ ${ }^{b}$ Elektrik Elektronik Mühendisliği Bölümü, Düzce Üniversitesi, Düzce, TÜRKIYE \\ *Sorumlu yazarın e-posta adresi: beytullahbozali@duzce.edu.tr
}

DOI : 10.29130/dubited.659075

\begin{abstract}
ÖZET
Güç sistemlerinde gerilim ve açı kararsızlığı gibi olumsuz nedenlerden dolayı güç sisteminin hızı bir şekilde gözlenebilmesi ve kontrol edilmesi gerekmektedir. Fazör Ölçüm Birimi (FÖB) teknolojisi bu gereksinimi karş1layan oldukça yeni bir teknolojidir. Güç sisteminde kullanılan FÖB'lerin maliyetleri yüksek olduğu için, sistemindeki baralara optimum şekilde yerleştirilmesi önemlidir. Sistemi tamamen gözlenebilir kılan en az sayıda FÖB'lerin belirlenmesi için farklı metotlar kullanılmaktadır. Önerilen metotların görevi, sistemdeki baralara bağlanacak FÖB sayısını azaltmak ve FÖB'lerin kurulum maliyetini minimuma indirgemektir. Bu çalışmada, optimal çözüm için benzetimler Matlab programı kullanarak ve Matlab ile uyumlu çalışan PSAT programdan yararlanılarak yapılmıştır. Çalışmalar Derinlik Arama Metodu, Graf Teorisi Metodu ve Yinelemeli N-1 Güvenlik metotları ile gerçekleştirilmiştir. Bu yöntemler Türkiye $400 \mathrm{kV}$ 'luk güç sistemi üzerinde uygulanmıştır. Bu çalışma sonucunda, güç sistemi kararsızlık durumuna gelmeden önlemler alınarak sistemin kararlı ve güvenilir olması için, en az sayıda FÖB kullanılarak güç sistemindeki hangi baralara yerleştirilmesinin uygun olacağı belirlenmiştir. Elde edilen simülasyon sonucunda hem maliyeti azaltmak hem de güç sisteminin tamamının gözlenmesinin sağlamak için optimum sayıda FÖB'leri hangi baralara yerleştirilmesi gerektiği bulunmuştur.
\end{abstract}

Anahtar Kelimeler: Gözlenebilirlik, Optimal FÖB Yerleşimi, Fazör Ölçüm Birimi, Derinlik Arama Metodu, Graf Teorisi Metodu, Yinelemeli N-1 Güvenlik Metodu.

\section{Determination of Optimal Phase Measurement Unit Settlements In the Turkey $400 \mathrm{kV}$ Power System}

\begin{abstract}
Due to negative reasons such as voltage and angle instability in power systems, the power system must be observed and controlled quickly. The Phasor Measurement Unit (PMU) technology is a fairly new technology that meets this requirement. Since the costs of the PMUs used in the power system are high, it is important to place them optimally in the busbars in the system. Different methods are used to identify the minimum number of PMUs that make the system fully observable. The task of the proposed methods is to reduce the number of PMUs to be connected to the busbars in the system and to minimize
\end{abstract}


the installation cost of the PMUs. In this study, simulations for the optimal solution were made by using Matlab program and PSAT program that works in harmony with Matlab. The studies were carried out with Depth Search Method, Graph Theory Method, and Recursive N-1 Security Methods.

Turkey has applied these methods on $400 \mathrm{kV}$ power system. As a result of this study, measures were taken before the power system becomes unstable, and it was determined which busbars in the power system would be suitable for using the minimum number of PMUs for the stability and reliability of the system. As a result of the simulation, it was found out which busbars should be placed in the optimum number of PMUs in order to both reduce the cost and ensure the observed of the whole power system.

Keywords: Observability, Optimal PMU Placement, Phasor Measurement Unit, Depth Search Method, Graph Theory Method, Recursive N-1 Security Method.

\section{GIRIS}

Güç sistemlerinde gerilim ve açı kararsızlı̆̆ı gibi olumsuz nedenlerden dolayı güç sisteminin hızlı bir şekilde gözlenebilmesi ve kontrol edilmesi gerekir [1]. Fazör Ölçüm Birimi (FÖB)'ler, ayrık Fourier prensibi ile çalışırlar. FÖB'ler güç sistemindeki akım ve gerilimi fazör olarak ölçebilen cihazdır [2]. Küresel konumlandırma sistemi (GPS) kullanması, bilgisayar geçişi uygulamaları için örneklenmiş veri işleme tekniklerine ek olarak, FÖB'lerin daha fazla gelişmesine katkı sağlamıştır. FÖB'ler arasındaki senkronizasyon, aynı zamanda voltajın ve akım dalga formlarının küresel konumlandırma sisteminden gelen ortak bir senkronizasyon sinyali kullanılarak aynı anda örneklenmesiyle sağlanır. Aynı zaman aralığında bir güç sisteminin farklı veri yollarından fazörler elde etmek, durum tahmini ve kararlılık analizi gibi çeşitli uygulama alanlarında izlenen kontrol sisteminin performansını iyileştirebilir [3]. 1990 yılında ilk FÖB Vircinia Technology tarafından tasarlanmıştır [4]. İlk kez 1995 yılında The Institute of Electrical and Electronics (IEEE) FÖB standarttı yayınlanmıştır. Yayınlanan standart 2005 yılında C37.118-2005 yenilenmiştir [5]. FÖB'leri güç sistemlerinde gelişmiş gözlenebilirlik ve sistemin kontrol edilebilmesi için kullanılan cihaz olarak tanımlanmıştır [6].

Bir güç sistemini gözlemlenebilirliği analizini yürütmek için üç temel yaklaşım vardır. Bunlar: sayısal, topolojik ve hybrid yaklaşımlarıdır [7-8]. Sayısal gözlemlenebilirlik yaklaşımı, durum vektörü için benzersiz bir çözümün sunmaktadır. Oluşan matrisin tekil veya eşdeğer olmadığı durumlarda Jacobian matrisinin tam bir sütun sırasına sahip ve iyi sınırlandırılmış olması koşuluyla tahmin edilebileceği vurgulanmaktadır. Topolojik gözlemlenebilirlik yaklaşımı, ölçüm kümesinin tam dereceli en az bir ölçüm ağacı oluşturabilmesi durumunda bir ağın tamamen gözlenebilir olması gerçeğine dayanır [9-10]. Hybrid gözlemlenebilirlik yaklaşımı iki ya da daha çok farklı network topolojisinin karma olarak kullanıldığ 1 topoloji şeklidir.

Geniş alanlı güç şebekesinin her bir barasına bir FÖB takılması ekonomik değildir. Sonuç olarak, optimum FÖB yerleştirme problemi, minimum sayıda FÖB ile tam gözlemlenebilirlik elde etmek için bir güç sistemine hangi baralara ve kaç adet FÖB yerleştirilmesi gerektiği ile ilgilidir. Sistem ölçüm modelini gözlemlenebilir kılmak için minimum fazör ölçü birimlerinin yerleştirilmesi bu makalenin temel amacıdır. Literatürde yapılan çalışmaları incelersek, bu çalışmalardan bir güç sistemi gözlenebilirliği için Tabu Search algoritması ile optimum FÖB yerleşimi geliştirilmiştir [11]. Abdelaziz vd. [12] optimal yerleşim problemlerinde hesaplama yükünü azaltmayı amaçlayan üç yaklaşım vurgulamaktadır. Derinlik İlk Arama, Simüle Edilmiş Tavlama ve Minimum Yayılma Ağacı, farklılıkları ve ilişkileri detaylı bir şekilde tartışılmaktadır. Yakınsama hızını arttırmak için, güç sistemine ilk FÖB yerleşimini graf teorisi yöntemi kullanılmaktadır. Diğer bir çalışmada güç sistem gözlemlene bilirliğinin analizi ve FÖB yerleştirme kuralları kesin bir şekilde sunulmuştur. En iyi yerleşim kalite ve verimlilik dengesini iyi korur. Derinlik Arama Yönteminin optimizasyon kuralı iyileştirilerek sonuçların çeşitliliği geliştirilmiştir. Farklı IEEE test sistemine uygulayarak optimum FÖB 
sayısı ve yerleştirilmesi gereken baraları bulmuştur [13]. Bir diğer çalışmada, Illk Derinlik arama, Graf Teorisi, Benzetilmiş Tavlama, Yeniden Dönen Ağaç ve Doğrudan Yayılan Ağaç gibi farklı yöntemler kullanarak FÖB'lerin optimum yerleşimi için Güç Sistemi Analizi Araç Kutusu (PSAT) kullanılmıştır. Sonuçlar, Tamsayılı Doğrusal Programlama (ILP) yöntemi sonuçlarıyla da karşılaştırılmıştır [14]. Nuqui vd. [15] yazarlar yeni bir metot sunmuşlardır. Sunulan bu metot, güç sisteminde optimal FÖB yerleştirilecek baraları bulmak için kapsayan ağaç graf yöntemi kullanmış. Sistemde gözlemlenmeyen bölgeler FÖB tarafından gözlenene kadar kademe kademe azalır. Bu çalışmada da Graf Teorisi yaklaşımından da bahsedilmiştir [16]. Optimal FÖB yerleşimi bulmak için Genetik Algoritma kullanmışlardır. Sistemi gözlemlenebilir hale getirmek için gereken minimum FÖB sayısı, bir bara sıralaması metodolojisi kullanılarak bulunur. FÖB yerleştirme işlemi, maksimum kapsama alanına sahip bir veya daha fazla baralarla başlar. Gaovd. [17] Güç sistemi çalışma durumlarının tam olarak gözlenebilirliğini ve nesnel bir işlev olarak en az sayıda fazör ölçüm birimini göz önünde bulundurarak, iyileştirilmiş bir optimum FÖB yerleştirme algoritması önerilmiştir. Bu algoritmada, genetik algoritma (GA), optimum çözümün elde edilmesini sağlamak için parçacık sürüsü optimizasyonu (PSO) algoritması ile etkili bir şekilde birleştirmişlerdir. Ek olarak, sözde ölçüm adı verilen hızlı bir gözlemlenebilirlik analiz yöntemi ileri sürmüşlerdir.

Çalışmalar Türkiye $400 \mathrm{kV}$ 'luk iletim sistemi üzerinde uygulanmıştır. Bu çalışma sonucunda güç sisteminde kararlılığının sağlanabilmesi için en az sayıda FÖB kullanılarak güç sistemindeki hangi baralara yerleştirilmesinin uygun olacağ 1 belirlenmiştir. Elde edilen simülasyon sonucunda hem maliyeti azaltmak hem de güç sisteminin tamamının gözlemlemek için optimum sayıda FÖB'leri hangi baralara yerleştirilmesi gerektiği bulunmuştur.

\section{MATERYAL VE METOD}

\section{A. FAZÖR ÖLÇÜM BİRİMI (FÖB) TEKNOLOJÍSİ VE YAPISI}

FÖB'ler bir güç sisteminde zaman senkronize olarak fazör ölçümleri sağlar [18]. FÖB ölçümlerinde senkronizasyon, global konumlandırma sisteminden (GPS) gelen ortak bir senkronizasyon sinyali kullanılarak voltaj ve akım dalga formlarının zaman bilgisi kullanılarak işlenmesiyle sağlanır. Senkronize fazörü hesaplama yeteneği, güç sisteminin izlenmesi ve kontrolü, gelecekte FÖB cihazlarının önemini arttırmaktadır. Şekil 1'de, Virginia Tech ait ilk FÖB donanım blok şeması verilmiştir. Sonuç olarak, Şekil 1'de gösterilen yapı bir bilgisayar rölesine paraleldir. Analog girişler, akım ve gerilim transformatörlerinin ikincil sargılarından elde edilen akımlar ve gerilimlerdir. Her üç faz akım ve gerilimi de kullanılır, böylece pozitif dizi ölçümü yapılabilir. Bir rölenin aksine, bir FÖB, trafo merkezinde çıkan çeşitli besleyicilerde akımlar ve trafo merkezindeki çeşitli baralara ait gerilimleri ölçerler. Akım ve voltaj sinyalleri, uygun şöntler veya cihaz transformatörleriyle (tipik olarak \pm 10 volt aralığında) voltajlara dönüştürülür, böylece analog-dijital dönüştürücülerin gereksinimleriyle eşleşirler.

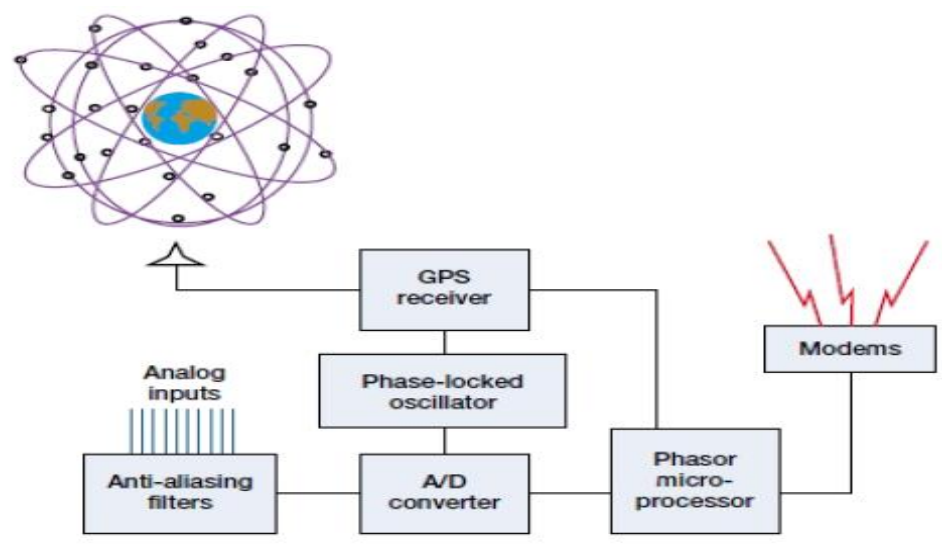

Şekil 1. FÖB temel blok şeması [19] 
Bir fazör ölçüm birimi, $50 / 60 \mathrm{~Hz}$ AC dalga formlarını (voltajlar ve akımlar) tipik olarak çevrim başına 48 numune hızında ölçebilen, modern dijital sinyal işlemcileri kullanan bir cihazdır. Küresel Konumlandırma Sistemi (GPS) referans kaynağı ile birlikte faz kilitli bir osilatör, 1 mikro saniye hassasiyetle gerekli yüksek hızlı senkronize örnekleme sağlar. Hat frekansları ayrıca her sahadaki FÖB tarafından hesaplanır. Bu fazör ölçümü yöntemi, yüksek bir çözünürlük ve doğruluk derecesi sağlar. Elde edilen zaman etiketli fazörleri, saniyede 50/60 numuneye kadar oranlarda yerel veya uzak bir alıciya iletilebilir [12].

FÖB güç sistemlerinde gerilim ve akım fazörlerinin anlık ve zaman etiketli olarak hassas ölçüm yapabilen cihazlar olarak üretilmişlerdir [20]. Şekil 2'de bir alanda fazör ölçüm senkronizasyonunun ölçüm birimi verilmiştir.

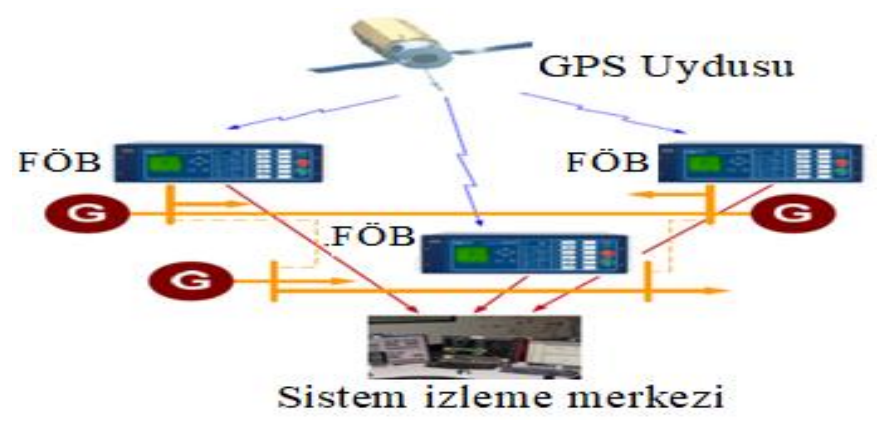

Şekil 2. FÖB senkronizasyonuna dayalı geniş alan ölçüm birimi

Şebekeye uygun olan ve birbirinden uzakta olan her bir noktasına FÖB'lerin yerleştirilmesi ile GPS'den gelen senkronizasyonu sağlanmış örneklemeli akım ve gerilim dalga şeklinin aynı zamanda ölçülmektedir. Güç şebekelerinin ayrıntılı gözlemlenebilmesi için, güç sistemlerinin arızalarının önceden tespit edilebilmesi, sistemin yük akış durumlarının akıcı ve anlık olarak gözlemlenmesi, sağlanmış olur [21]. Güç sistemlerinde, anlık değişimlerinin en yoğun olduğu baralardan ölçümler alınması fazör ölçüm sistemlerinin hesaplı ve kullanışlı olması açısından önemlidir [22].

\section{B. GÜÇ SISTEMI GÖZLENEBİLİRLİK ANALIZII VE FÖB YERLEŞTÍRME KURALLARI}

\section{B.1. Güç Sistemlerinde Gözlemlenebilirlik Analizi}

Güç sisteminin gözlenebilirliği, FÖB'lerin güç sistemine optimal şekilde yerleştirilmesinin sonucudur. Yeni bir FÖB güç sistemine yerleştirildikten sonra, hangi yöntem kullanılırsa kullanılsın, güç sisteminin gözlenebilirliği kontrol edilmelidir. Sistem gözlenebilir ise, FÖB yerleştirme durur, aksi takdirde sisteme FÖB yerleştirmeye devam edilmelidir. Rastgele girişler için, sınırlı bir süre boyunca, çıktı girişi benzersiz bir şekilde tespit edebiliyorsa, o zaman güç sisteminin durumu gözlemlenebilirlik olarak adlandırılır. Sistemin gözlenebilir olup olmadığını incelemek için, güç sistemi sayısal gözlemlenebilirliği ve topoloji gözlemlenebilirliği olmak üzere iki şekilde analiz edebiliriz [23].

\section{B.1.1. Sayısal Gözlemlenebilirlik}

Denklem 1'de kullanarak N düğümlü ve m ölçümlü bir güç sistemini tanımlanır.

$z=H x+v$

Denklem 1'de z, m boyutlarının metrik vektörü $\mathrm{H}, \mathrm{m}^{*}(2 \mathrm{~N}-1)$ boyutlarının Jacobian matrisi $\mathrm{x}, 2 \mathrm{~N}-1$ boyutlarındaki voltaj vektörü $v$, ise $m$ boyutunun metrik gürültü vektörü olarak ifade etmektedir.

Metrik Jacobian matrisi tekil ve iyi şartlandırılmış ise, Rank $(\mathrm{H})=2 \mathrm{~N}-1$ değerine sahipse, güç sistemi sayısal gözlenebilir olarak adlandırılır [13]. 


\section{B.1.2. Topolojik Gözlemlenebilirlik}

Ayrıştırılmış ölçüm modelini ve graf teorisini kullanılır. Bu yöntemlerde karar, mantıksal işlemlere dayanır. Burada güç sistemi gözlemlenebilir olabilmesi için, mevcut ölçüm sistemi ile birlikte bir sıralama ağacı oluşturmaktadır. Sıralama oluşturabilmesi için ağ bağlantısı, ölçüm türleri ve konumları hakkında bilgi ihtiyaç vardır [12]. Topoloji bir güç sistemini temsil etmek için kullanıldığında, sistem $n$ uçları içeren bir graf olarak ve b kenarları olan bir graf olarak dikkate alınabilir. Buradaki n baraları ve b iki barayı birbirine bağlayan hatları temsil eder.

$G=(V, E)$

V: Graftaki tepe noktalarının (dügümlerin) kümesidir.

E: Graftaki kenarların kümesidir.

Alt graf tanımı:

$\mathrm{G}^{\prime}=\left(\mathrm{V}^{\prime}, \mathrm{E}^{\prime}\right)$

$\mathrm{V}^{\prime} \subseteq \mathrm{V}$, ve $\mathrm{E}^{\prime} \subseteq \mathrm{E}$

Genellikle, eğer bir alt grafta, G'nin tüm düğümlerini içeren, yani $\mathrm{V} \subseteq \mathrm{V}^{\prime}$ olan bir $\mathrm{G}^{\prime}$ var ise, bu güç sistemi topolojik olarak gözlemlenebilir olarak kabul edilir [24].

\section{FÖB'LERIN YERLEŞTİRILMESINNE DİKKAT EDİLECEK HUSUSLAR}

FÖB'ler bara akım ve gerilimlerinin fazör ölçümlerini sağladıkları için buradaki esas amaç, bulunan sınırlamalar içinde güç sisteminin topolojik olarak gözlemlemek ve sisteme konulması gereken minimum sayıdaki FÖB sayılarını ve bu FÖB'lerin hangi baralara yerleştirilmesi gerektiğinin bulunmasıdır. FÖB'lerin optimum şekilde baralara yerleştirilmesi bir optimizasyon problemidir. FÖB'lerin yerleştirilmesinde dikkat edilecek hususlar sırasıyla verilmiştir.

- FÖB konulduğu baranın gerilimi ile bu bara ya bağlı her kolun akımının ölçümü biliniyor olsun. Șekil 3.a'da verilmektedir. (Ölçülen değer).

- FÖB konulduğu bara ya bağlanan her bir kolun diğer ucundaki gerilim değeri biliniyor olsun. (Hesaplanan değer).

- Gerilimleri belirlenen iki bara arasındaki iletim hattının akım değeri biliniyor kabul edilsin. Şekil 3.b. (Hesaplanan değer).

- Kirşofun akım yasası kullanılarak hesaplanabilen, tüm iletim hattın akım değeri biliniyor olsun. (Hesaplanan değer). (Pseudo akım ölçümü). Şekil 3.c'de verilmektedir [25].

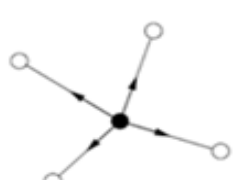

(a)

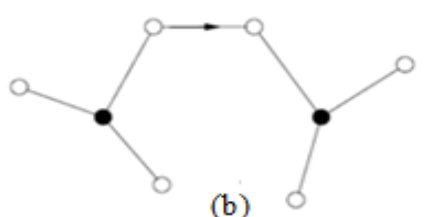

(b)

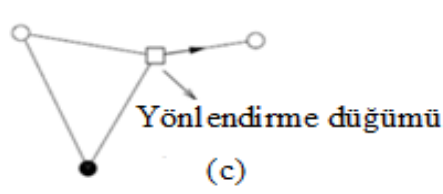

(c)

Şekil 3. FÖB'lerin yerleşim kuralları

\section{C.1. FÖB'lerin İlk Yerleşim Yerinin Tespit Edilmesi}

Güç sistemi iletim şebekesinde FÖB'ün ilk yerleştirilmesi gereken baranın belirlenmesi, graf teorisi kullanılarak yapılmaktadır [21]. FÖB'lerin ilk yerleşim yerinin tespit edilmesi için dikkat edilecek hususlar sırasıyla verilmiştir.

- FÖB konulmuş her bir iletim hattına akım fazör ölçümü atanır.

- İletim sistemindeki, gerilim değerleri bilinen iki barayı birbirine bağlayan her iletim hattına hesaplanan akım fazörü atanır. 
Kurallar ile prosedürler güç sisteminin gözlenen kısmından, gözlenemeyen kısmına doğru ağaç oluşturacak şekilde adım adım genişlemektedir. Prosedürler sırasıyla aşağıdaki gibi gerçekleşir.

- FÖB konulmuş bir baradan başlanılarak ve bir dügümden diğer bir komşu düğüme ilerlenmektedir.

- Her aşamada, gözlenemeyen kısımdan en fazla dala sahip bara ya bir FÖB cihazı konularak güç sisteminin gözlenebilirliği genişletilmektedir [20].

- Ağaç, verilen bir iletim hattı boyunca daha fazla genişletilemiyor ise, bir önceki düğüm noktasına geri dönerek yeni bir iletim hattı seçilir.

- Prosedürler tamamlandığında güç sisteminin tümü gözlenebilir olduğunda, sisteme yerleştirilen FÖB'lerin sayısı belirlenir. Bu FÖB'ler başlangıç tahmini olarak kabul edilmektedir ve benzerlik yolları ile bu kümenin büyüklüğü azaltılmaya çalışılmaktadır [20].

\section{FÖB YERLEŞTIRME PROBLEMİ FORMÜLASYONU}

Belirli bir veri yoluna yerleştirilmiş bir FÖB, veri yolunun gerilim fazörü ve bu veri yoluna gelen tüm hatlar için fazör akımlarını ölçebilir. Böylece, FÖB'ler sistemdeki stratejik baralara yerleştirilmesiyle tüm sistem gözlenebilir hale getirile bilinir [26]. FÖB yerleşiminin amacı, tam ağ gözlemlenebilirliği elde etmek için FÖB'lerin sayısını en aza indirmektir. Aslında, FÖB'lerin yerleştirilmesi gereken baraların kümesi, grafın baskın bir grubuna karşıılık gelir [27]. G grafındaki baskın birtakım köşeler veya G'deki her bir köşeye egemen olan köşeler ya egemen kümeye dahil edilir ya da egemen kümedeki bir veya daha fazla köşeye bitişiktir [28]. Bu nedenle, optimal FÖB yerleşimi problemi graftaki en küçük baskın küme problemine eşlenir [27]. FÖB'lerin, ilgili veri yolundaki gerilim fazörlerinin ve bu veri yolundan çıkan tüm hatların akım fazlarını ölçmek için yeterli kanala sahip olduğu varsayılmaktadır [26]. Güç sisteminde, tüm bitişik veri yollarının gerilim fazörleri, bu veri yoluna gelen hatlar boyunca izlenen fazör akımları ve bilinen hat parametreleri kullanılarak çözülebilir olacaktır [29]. Bu çalışmada optimal FÖB yerleşimi probleminin çözümü için bir tam sayılı doğrusal programlama tabanlı formülasyonu kullanılmıştır.

\section{D.1. Tamsayılı Programlama: Problem Formülasyonu}

Bir n-bara sistemi için optimal FÖB yerleşimi problemi aşağıdaki gibi formüle edilebilir [26]. FÖB'lerin yerleştirilmesi problemini optimizasyon problemine dönüştürmek için amaç ve kısıt fonksiyonları tanımlanmalıdır. Amaç fonksiyonu oluşturulurken FÖB'lerin fiyat bilgileri de dikkate alınmalıdır. Fakat, bu çalışmada tüm baralar da kullanılan FÖB'lerin aynı fiyatta olduğu düşünülerek problem çözülmüştür [27]. Amaç ve kısıt fonksiyonları Denklem 3 ve Denklem 4'te verilmektedir.

$\min \mathrm{J}(\mathrm{x})=\sum_{i=1}^{n} w_{i} \cdot x_{i}$

$f(x)=A \cdot x \geq 1$

Denklem 4'teki x, i. girişi olan bir ikili karar değişkeni vektörüdür. Denklem 3'teki xi eğer i. veri yoluna bir FÖB kuruluysa 1'e eşittir; aksi takdirde 0'dır. Denklem 3'teki wi, i veri yoluna kurulmuş FÖB'lerin maliyetidir ve Denklem 4'teki $\mathrm{f}(\mathrm{x})$ bir vektör işlevidir. A matrisi binary bağlantı girişleri şöyle tanımlanır:

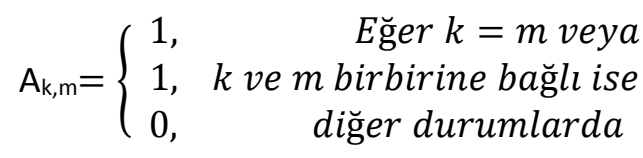

FÖB'lerin yerleştirilmesinde Denklem 5 dikkate alınır. Bu denkleme göre karar değişkenleri FÖB'lerin olması durumda " 1 ", FÖB'lerin olmaması durumunda ise "0" değerini alırlar. 
Türkiye $400 \mathrm{kV}$ 'luk enterkonnekte güç sistemini modellenmesi için, şekil 4'te, IEEE 14-baralı test sistemi örnek modellenmesi dikkate alınarak Türkiye $400 \mathrm{kV}$ 'luk iletim sistemine uyarlanmıştır. Sistemin optimum şekilde FÖB yerleştirmek için tam sayılı doğrusal programlama yaklaşım metodu kullanılmıştır.

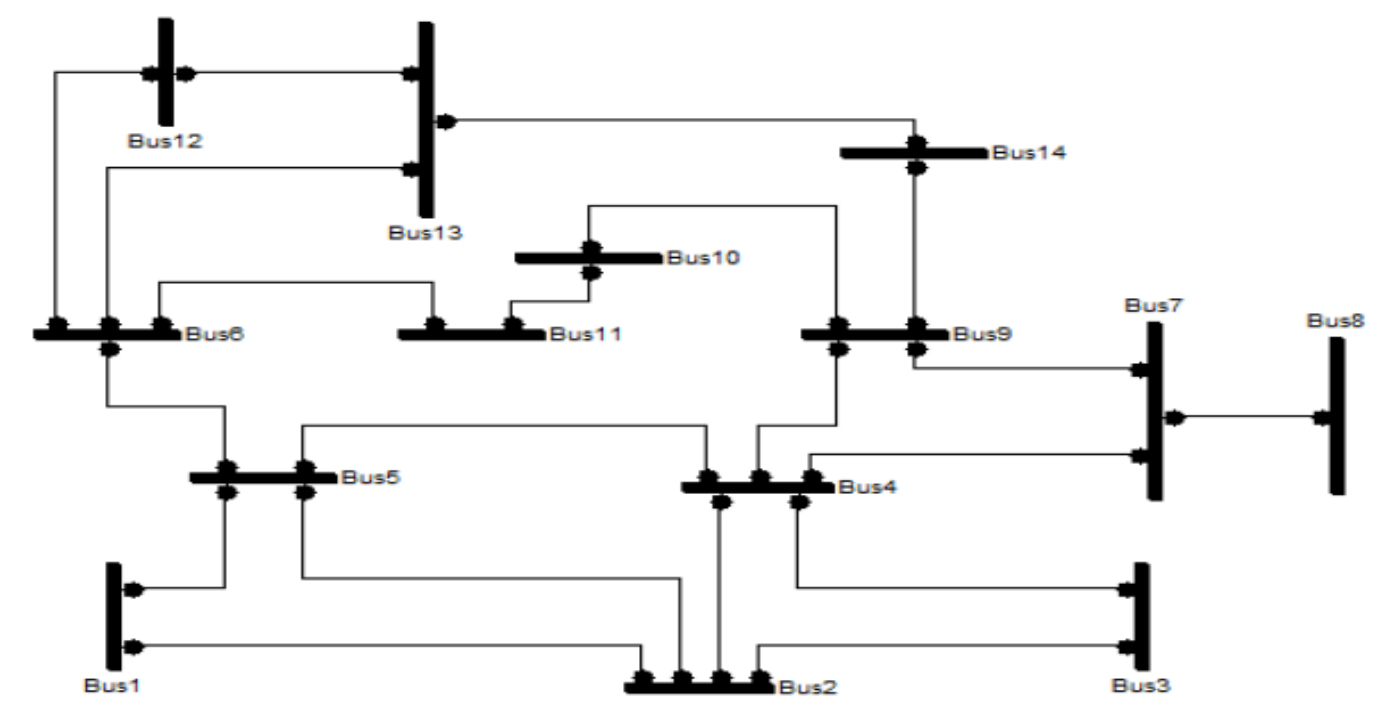

Şekil 4. IEEE 14 baralı test sisteminin tek hat şeması

IEEE 14 baralı test sisteminin problem formülasyon Denklem 6'da verilmektedir [30].

$\min \mathrm{J}(\mathrm{x})=\sum_{i=1}^{14} w_{i} \cdot x_{i}$

Yaptığımız çalışmayı modellersek, Türkiye $400 \mathrm{kV}$ 'luk mevcut olan enterkonnekte güç sisteminin problem formülasyonu Denklem 7'de verilmiştir. Denklem 8'de Türkiye 400 kV'luk enterkonnekte güç sistemi için planlanan yeni baraların devreye alınması durumunda problem formülasyonu verilmektedir.

$\min \mathrm{J}(\mathrm{x})=\sum_{i=1}^{160} w_{i} \cdot x_{i}$

$\min \mathrm{J}(\mathrm{x})=\sum_{i=1}^{167} w_{i} \cdot x_{i}$

14 baralı güç sistem matris formuna çevrilirken Denklem 5'teki kural uygulanarak i. bara için kendine ve bağlı olduğu bir diğer bara için "1" değeri atanır. Diğer durumlar için " 0 " değeri atanarak matris formu tablo 1'deki gibi oluşturulur.

Tablo 1. IEEE 14-baralı test sisteminin matris formu

\begin{tabular}{ccccccccccccccc}
\hline Bara No & $\mathbf{1}$ & $\mathbf{2}$ & $\mathbf{3}$ & $\mathbf{4}$ & $\mathbf{5}$ & $\mathbf{6}$ & $\mathbf{7}$ & $\mathbf{8}$ & $\mathbf{9}$ & $\mathbf{1 0}$ & $\mathbf{1 1}$ & $\mathbf{1 2}$ & $\mathbf{1 3}$ & $\mathbf{1 4}$ \\
\hline $\mathbf{1}$ & 1 & 1 & 0 & 0 & 1 & 0 & 0 & 0 & 0 & 0 & 0 & 0 & 0 & 0 \\
\hline $\mathbf{2}$ & 1 & 1 & 1 & 1 & 1 & 0 & 0 & 0 & 0 & 0 & 0 & 0 & 0 & 0 \\
\hline $\mathbf{3}$ & 0 & 1 & 1 & 1 & 0 & 0 & 0 & 0 & 0 & 0 & 0 & 0 & 0 & 0 \\
\hline $\mathbf{4}$ & 0 & 1 & 1 & 1 & 1 & 0 & 1 & 0 & 1 & 0 & 0 & 0 & 0 & 0 \\
\hline $\mathbf{5}$ & 1 & 1 & 0 & 1 & 1 & 1 & 0 & 0 & 0 & 0 & 0 & 0 & 0 & 0 \\
\hline $\mathbf{6}$ & 0 & 0 & 0 & 0 & 1 & 1 & 0 & 0 & 0 & 0 & 1 & 1 & 1 & 0 \\
\hline $\mathbf{7}$ & 0 & 0 & 0 & 1 & 0 & 0 & 1 & 1 & 1 & 0 & 0 & 0 & 0 & 0 \\
\hline $\mathbf{8}$ & 0 & 0 & 0 & 0 & 0 & 0 & 1 & 1 & 0 & 0 & 0 & 0 & 0 & 0 \\
\hline $\mathbf{9}$ & 0 & 0 & 0 & 1 & 0 & 0 & 1 & 0 & 1 & 1 & 0 & 0 & 0 & 1 \\
\hline $\mathbf{1 0}$ & 0 & 0 & 0 & 0 & 0 & 0 & 0 & 0 & 1 & 1 & 1 & 0 & 0 & 0 \\
\hline
\end{tabular}


Tablo 1 (devam). IEEE 14-barall test sisteminin matris formu

\begin{tabular}{lllllllllllllll}
\hline $\mathbf{1 1}$ & 0 & 0 & 0 & 0 & 0 & 1 & 0 & 0 & 0 & 1 & 1 & 0 & 0 & 0 \\
\hline $\mathbf{1 2}$ & 0 & 0 & 0 & 0 & 0 & 1 & 0 & 0 & 0 & 0 & 0 & 1 & 1 & 0 \\
\hline $\mathbf{1 3}$ & 0 & 0 & 0 & 0 & 0 & 1 & 0 & 0 & 0 & 0 & 0 & 1 & 1 & 1 \\
\hline $\mathbf{1 4}$ & 0 & 0 & 0 & 0 & 0 & 0 & 0 & 0 & 1 & 0 & 0 & 0 & 1 & 1 \\
\hline
\end{tabular}

1. bara 2 ve 5 . baralara bağlıdır. Diğer bir ifade ile, 1. baraya koyulan bir FÖB ile 2, 5 nolu baralardaki akım, gerilim ve faz açıları gözlemlenebilir. Aynı şekilde 5. bara 1, 2, 4, 6. baralara bağlıdır. Diğer bir ifadeyle, 5. baraya koyulan bir FÖB ile 1, 2, 4, 6 nolu baralardaki akım, gerilim ve faz açıları gözlemlenebilir. 14 baralı bir güç sistemi olduğunda $14 \mathrm{X} 14$ boyutunda bir matris oluşturulur. Uygulamamız Türkiye 400 kV'luk mevcut olan enterkonnekte güç sisteminin için 160x160'llk ve Türkiye $400 \mathrm{kV}$ 'luk enterkonnekte güç sistemi için planlanan yeni baralar ve iletim hatları devreye alınması durumunda $167 \times 167$ boyutunda bir matris oluşturularak matris formlarına dönüştürülürler.

IEEE 14 baralı test sistemin matris formu kısıt fonksiyonuna çevrilmiş halleri Denklem 9'da verilmektedir [31]:

$f(x)=A . x= \begin{cases}f 1=x 1+x 2+x 5 & \geq 1 \\ f 2=x 1+x 2+x 3+x 4+x 5 & \geq 1 \\ f 3=x 2+x 3+x 4 & \geq 1 \\ f 4=x 2+x 3+x 4+x 5+x 7+x 9 & \geq 1 \\ f 5=x 1+x 2+x 4+x 5+x 6 & \geq 1 \\ f 6=x 5+x 6+x 11+x 12+x 13 & \geq 1 \\ f 7=x 4+x 7+x 8+x 9 & \geq 1 \\ f 8=x 7+x 8 & \geq 1 \\ f 9=x 4+x 7+x 9+x 10+x 14 & \geq 1 \\ f 10=x 9+x 10+x 11 & \geq 1 \\ f 11=x 6+x 10+x 11 & \geq 1 \\ f 12=x 6+x 12+x 13 & \geq 1 \\ f 13=x 6+x 12+x 13+x 14 & \geq 1 \\ f 14=x 9+x 13+x 14 & \geq 1\end{cases}$

Uygulamamızda Türkiye $400 \mathrm{kV}$ 'luk mevcut olan enterkonnekte güç sisteminin için sistemin matris formu kısıt fonksiyonuna çevrilmiş halleri f1, f2, .....f160 (toplamda 160 adet farklı fonksiyon) olarak tanımlanır. Türkiye $400 \mathrm{kV}$ 'luk enterkonnekte güç sistemine yapılmakta olan baralar ve iletim hatları dahil edildiğinde sistemin matris formu kısıt fonksiyonuna çevrilmiş halleri f1, f2, f167 (toplamda 167 adet farklı fonksiyon) olarak tanımlanır.

Burada;

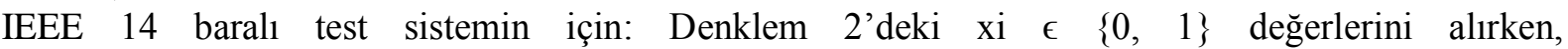
$\mathrm{i}=1,2,3,4,5, \ldots \ldots \ldots \ldots . .14$ değerlerini alır.

Türkiye 400 kV'luk mevcut olan enterkonnekte güç sisteminin için: Denklem 2'deki xi $\epsilon\{0,1\}$ değerlerini alırken, $\mathrm{i}=1,2,3,4,5 \ldots \ldots \ldots \ldots 160$ sayı değerlerini alır.

Türkiye $400 \mathrm{kV}$ 'luk enterkonnekte güç sistemine planlanan yeni baralar ve iletim hatları devreye alınması durumunda denklem 2'deki xi $\epsilon\{0,1\}$ değerleri alırken, $i=1,2,3,4,5, \ldots \ldots \ldots \ldots, 167$ say1 değerlerini alır. 


\section{E. FÖB'LERIN GÜÇ SISSTEMINE YERLEŞTİRILME METOTLARI}

FÖB'ler sistemde yerleştirilen baraların akım ve gerilim fazör ölçüm bilgileri sağladıklarından, hedef optimum adet FÖB ve bu FÖB'lerin sistemdeki hangi baralara konulması gerekmekte olduğunun belirlenmesidir. Bunun içinde, FÖB'lerin güç sistemine optimum şekilde konulmasını amaçlayan yöntemler önerilmiştir [32-33]. Literatür taranması yapıldığında güç sistemine FÖB yerleşimi için sezgisel yöntemler ve sezgisel olmayan yöntemler kullanılmaktadır. Bu yöntemlerden bazıları, Derinlik Arama Metodu, Graf Teorisi Metodu, Benzetilmiş Tavlama Metodu, Yeniden Dönen Ağaç Metodu ve Doğrudan Yayılan Ağaç Metodu gibi farklı yöntemler kullanılmıştır. Çalışmamız da, Derinlik Arama Metodu, Graf Teorisi Metodu ve Yinelemeli N-1 Güvenlik metodu uygulanmıştır. Bu metotlar, Türkiye 400 kV'luk mevcut olan enterkonnekte güç sistemi üzerinde ve Türkiye 400 kV'luk enterkonnekte güç sistemine ek olarak yapılmakta olan baralar ve iletim hatları dahil edildiğinde oluşan güç sistemleri üzerinde uygulanmıştır.

\section{E.1. Derinlik Arama Metodu}

$\mathrm{Bu}$ algoritma en çok kullanılan FÖB yerleştirme metotlarından biridir. Bu metotta FÖB yerleşim kurallarından sırasıyla ilk üç kural kullanır. Sistemdeki düğümlerin dal sayıları incelenir, en çok dala sahip düğüm bulunur [25]. İlk FÖB en çok kola sahip olan bu baraya yerleştirilir. Eğer bu özelliğe sahip birden çok bara var ise, bir tanesi rastgele seçilir. Diğer FÖB'ler ise şebeke tamamıla gözlenebilir hale gelinceye kadar aynı şekilde yerleştirilir. Şekil 5'te derinlik metodu iş akış şeması verilmektedir. Şebekede ölçülemeyen bir dal akımı ya da gerilimi kaldığı zaman, geriye dönüş yapılarak yeniden süreç başlatılır. Algoritmanın temel çalışma mantığı, bütün olası düğüm noktalarının FÖB yerleşim kurallarına göre test edilmesi ve bu işlemin sistemin gözlenebilir hale gelinceye kadar devam ettirilmesidir [34]. Genel olarak, Derinlik arama metodu, hiçbir alt düğüm bulunmayana kadar bir ata dügümünden doğrudan alt düğümünden birine doğru bir ağaç şeklinde arama yapar. Arama işlemi ardından geri döner ve geçerli dügümün üst düğümünün başka bir alt dügümünden arama yapılır.

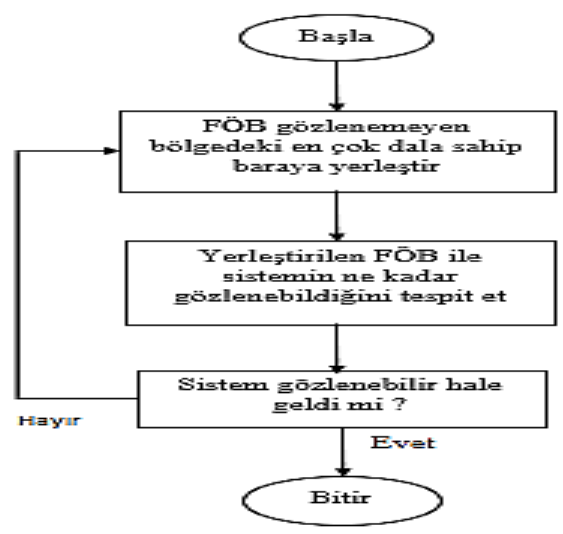

Şekil 5. Derinlik arama metodu akış şeması

Derinlik arama metodunun sınırlı arama süreleriyle en uygun veya en düşük seviyedeki bir çözüm bulunmasını sağlar. Derinlik arama metodu her zaman küresel en iyi çözümler yerine yerel en iyi çözümleri bulmaktadır. Lineer bir denklem ve derinlik arama metodu tarafından kullanılan açgözlü sezgisel algoritma (greedy heuristic algorithm), derinlik arama metodunun çok hızlı bir şekilde çözüm bulmasını sağlar [35].

\section{E.2. Graf Teorisi Metodu}

Graf teorisi metodu, derinlik metoduna benzemektedir. Tek farkı, Kirşofun akım yasası kullanılarak hesaplana bilinir olması ve tüm iletim hattın akım değerinin biliniyor varsayımını da dikkate alarak işlem yapmasıdır. Köşe adı verilen düğümlerden ve kenar adı verilen köşelerin birbirine bağlayan 
bağlantılardan oluşan veri yapısına graf denir. Graf, noktalar ve bu noktaları birleştiren çizgilerden meydana gelir. Şekil 6'da graf köşe ve kenar gösterimi verilmektedir.

Düğüm $\{1,2,3,4,5\}$

Kenar $=\{(1,2),(1,4),(2,3),(2,4),(2,5),(3,4),(3,5),(4,5)\}=\{\mathrm{e} 1, \mathrm{e} 3, \mathrm{e} 2, \mathrm{e} 6, \mathrm{e} 7, \mathrm{e} 8, \mathrm{e} 5, \mathrm{e} 4\}$

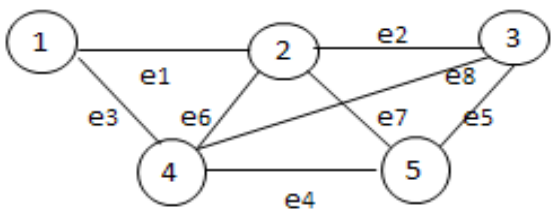

Şekil 6. Graf köşe ve kenar gösterimi [20]

Graf teorisi metodunun iş akış şeması şekil 5'te verilmekte olan derinlik metodu iş akış şeması ile aynıdır. FÖB konulmuş baraların dallarının akım fazör ölçümleri bulunurken, gerilim değeri bilinmekte olan iki barayı birbirine bağlamakta olan dalın akım fazör değerleri hesaplanır ve bulunanlara hesaplanan akım fazörü adı verilmektedir [20]. Derinlik arama metodu ve graf teorisi metodu arasındaki tek fark, sistemin tamamen gözlenebilir olup olmadığını bakmaktadır. Graf teorisi metodu bazı durumlarda, özellikle birleştirme yöntemi kullanıldığında, Derinlik arama metodu kıyasla daha iyi bir çözüm bulmayacaktır. Ayrıca, buradaki derinlik arama metodu doğası, yalnızca yerel optimal çözümleri önemseyen açgözlü bir algoritma olduğundan, alt dügümleri genişletme konusunda benzer bir yapıya sahiptir. Graf teorisi metodu, revize edilse bile, en uygun çözümleri bulamaması muhtemeldir [24].

\section{E.3. Yinelemeli N-1 Güvenlik Metodu}

Yenilemeli N-1 güvenlik metodu en az sayıda FÖB yerleştirmek için kurallar, bir ağ topolojisi ve ölçüm cihazlarının güvenilebileceği var saymaktadır. Elektrik kesinti durumunda (N-1 güvenliği) güç sisteminin tam olarak gözlemlenebileceğini sağlayabilecek kriterler olarak ileri sürmüştür. Aşağıdaki iki şarttan, biri geçerli olduğunda bir veri yolu barası olduğu söylenebilmektedir.

- İletim hattındaki düğümlere bir FÖB yerleştirilir;

- Belirlenen düğüme bir FÖB konularak en az iki dügüme bağlanır.

Eğer bara tek uçlu iletim hattına bağl1 ise, ikinci koşul dikkate alınmaz. Şekil 7'de önerilen N-1 güvenlik metodu için algoritmanın akış şeması verilmektedir [36].

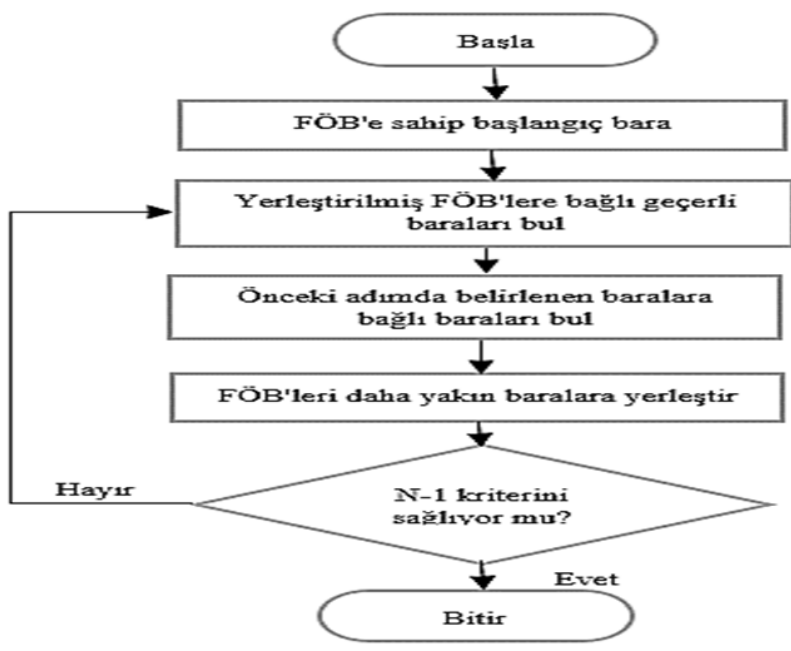

Şekil 7. Yinelemeli N-1 güvenlik metodu akışşeması 


\section{BULGULAR VE TARTIŞMA}

Bilgisayar destekli benzetim programlı olan Power System Analysis Toolbox (PSAT) programında Türkiye $400 \mathrm{kV}$ enterkonnekte güç sisteminin mevcut çalışmakta olan baralar ve iletim hattı ile devreye alınmamış hatlar (inşası devam eden) için güç sistemi ayrı ayrı modellenmiştir. Amaç güç sisteminin tamamını gözlemleyecek şekilde FÖB'lerin yerleştirmek olduğu için sistemin anlık üretim ve tüketim parametreleri gerekmemektedir. Aynı şekilde sisteme bağlı olan kompanzasyon sistemleri ihmal edilmiştir. Gerekli olan sadece sistemin bağlantı şemasıdır. Türkiye $400 \mathrm{kV}$ mevcut çalışmakta olan enterkonnekte güç sisteminin 160 bara ve 257 iletim hattından oluşmaktadır. Türkiye $400 \mathrm{kV}$ elektrik güç sisteminin devreye alınmamış hatlar (inşası devam eden) dikkate alındığında 167 bara ve 280 iletim hattından oluşmaktadır. Test işlemleri Intel i7-8550u $1.8 \mathrm{Ghz}$ işlemci ve 8GB RAM'a sahip bilgisayar üzerinde gerçekleştirilmiş̧ir. Çalışmalar Matlab 2018b programın kullanılarak PSAT programında Türkiye $400 \mathrm{kV}$ enterkonnekte güç sistemi modellenmiştir. Türkiye $400 \mathrm{kV}$ enterkonnekte güç sisteminin PSAT programında modellenmiş hali, şekil 8'de verilmektedir.

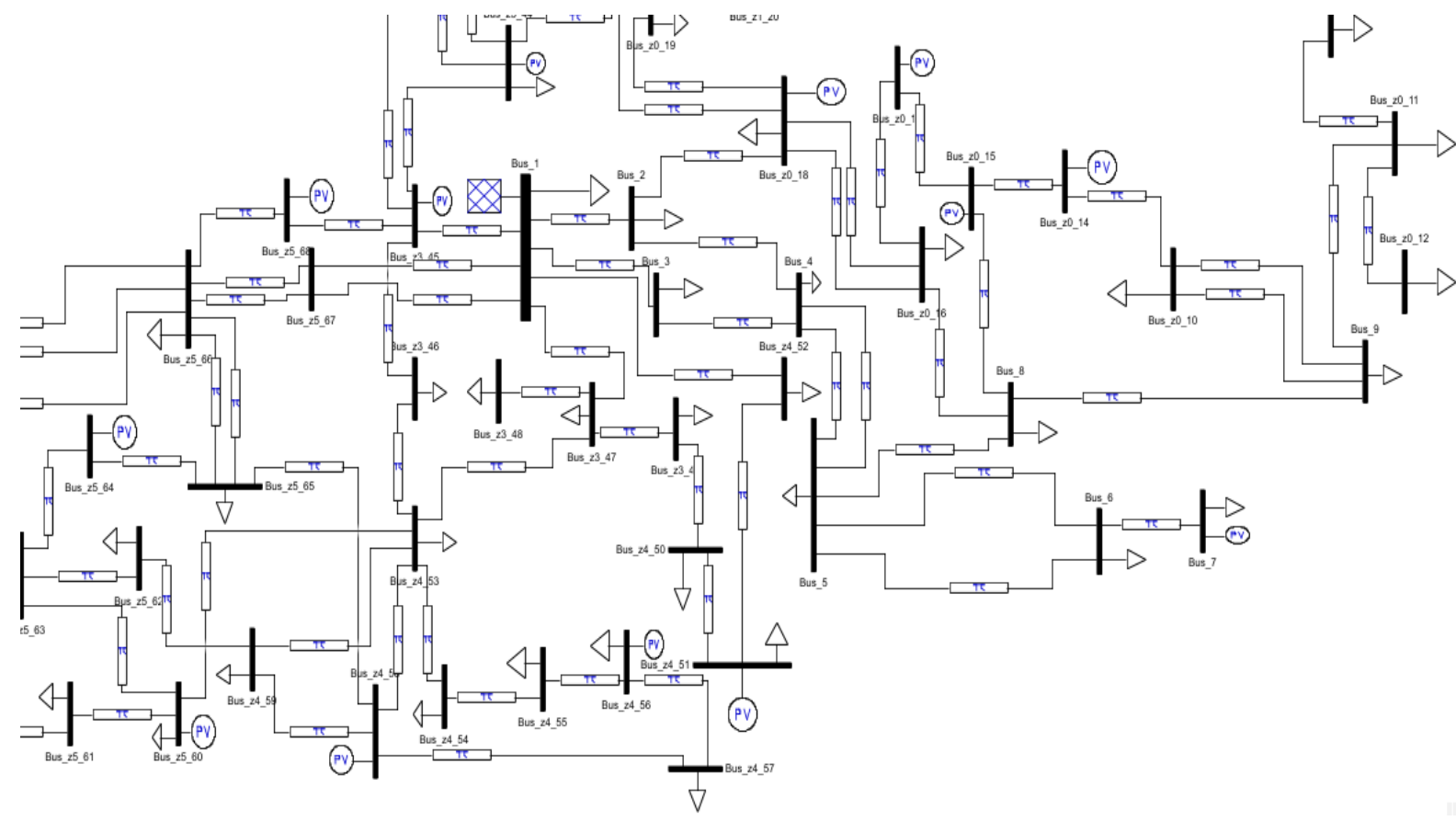

Şekil 8. Türkiye 400 kV'luk enterkonnekte güç sistemi güney doğu parçası PSAT modeli (Türkiye 400 kV'luk güç sistemin bir bölümü) [37]

\section{UYGULAMA 1. TÜRKIYYE 400 kV ENTERKONNEKTE GÜÇ SİSTEMİ}

Türkiye $400 \mathrm{kV}$ mevcut çalışmakta olan enterkonnekte güç sisteminin de 160 bara ve 257 iletim hattından oluşmaktadır. PSAT programı ile yinelemeli N-1 Güvenlik Metodu ve Matlab programı ile Derinlik Arama Metodu, Graf Teorisi Metodu güç sistemine uygulandığında elde edilen sonuçlar Tablo 2 'de verilmiştir. Enterkonnekte güç sistemini modellerken bara isimleri yerine bara numaraları kullanılmıştır. 
Tablo 2: Türkiye 400 kV'luk mevcut olan enterkonnekte güç sistemi FÖB yerleştirme sonuçları

\begin{tabular}{|c|c|c|c|}
\hline $\begin{array}{l}\text { Uygulanan } \\
\text { Yöntemler }\end{array}$ & $\begin{array}{l}\text { Geçen } \\
\text { Zaman }\end{array}$ & $\begin{array}{l}\text { Optimal Yerleştirilmesi } \\
\text { Gereken FÖB Sayısı }\end{array}$ & $\begin{array}{c}\text { Optimal FÖB Yerleştirilmesi Gereken } \\
\text { Baralar }\end{array}$ \\
\hline $\begin{array}{c}\text { Derinlik } \\
\text { Arama } \\
\text { Metodu }\end{array}$ & $0.087142 \mathrm{~s}$ & $e^{2}$ & $\begin{array}{l}1,5,7,9,11,15,16,19,23,25,27,28,32, \\
36,37,39,40,48,49,51,53,55,57,61,63, \\
65,66,70,72,75,82,83,85,88,91,92,93, \\
98,100,103,107,108,110,112,115,118, \\
120,124,126,130,132,138,142,144,146, \\
149,152,156,159\end{array}$ \\
\hline $\begin{array}{c}\text { Graf } \\
\text { Teorisi } \\
\text { Metodu }\end{array}$ & $0.099830 \mathrm{~s}$ & 59 & $\begin{array}{l}1,5,7,9,11,15,16,19,23,25,27,28,32, \\
36,37,39,40,48,49,51,53,55,57,61,63, \\
65,66,70,72,75,82,83,85,88,91,92,93, \\
98,100,103,107,108,110,112,115,118, \\
120,124,126,130,132,138,142,144,146, \\
149,152,156,159\end{array}$ \\
\hline $\begin{array}{c}\text { Yinelemeli } \\
\text { N-1 } \\
\text { Güvenlik } \\
\text { Metodu }\end{array}$ & $22.9288 \mathrm{~s}$ & 81 & $\begin{array}{l}2,3,5,6,9,11,14,15,16,19,23,24,26,29, \\
30,32,34,35,38,41,44,45,47,50,52,53, \\
55,57,61,62,63,65,66,67,70,72,73,75, \\
78,81,84,86,87,88,91,92,93,94,97,101, \\
102,104,105,107,109,112,115,116,118, \\
119,121,122,124,126,129,130,132,135, \\
137,139,140,143,144,146,148,150,152, \\
156,157,159,160\end{array}$ \\
\hline
\end{tabular}

Tablo 2'de Türkiye 400 kV'luk enterkonnekte güç sistemini uygulanan metotlarının karşılaştırılması verilmektedir. Şekil 9'da güç sistemine uygulanılan, Derinlik metodu, Graf teorisi metodu ve Yinelemeli N-1 Güvenlik metodu yerleşme süresi karşılaştıııldığında, Yinelemeli N-1 Güvenlik metodu 22.9288 sn ile güç sistemine FÖB'leri yerleştirmekte olduğu belirlenmiştir. Yinelemeli N-1 Güvenlik metodu güç sisteminde bulunan iletim hatlarını tek tek devre dışı bırakarak tüm sistemin gözlenebilmesini sağladığı için en uzun sürede sisteme FÖB'leri yerleştirmektedir. Diğer yöntemlerde sisteme yerleştirilen FÖB sayıları aynı olmakla birlikte yerleşme süreleri farklıdır. Enterkonnekte güç sistemini tamamen gözlemlenebilir olması için optimal FÖB yerleştirilmesi gereken baralar Tablo 2'de verilmektedir. Bu baralar Türkiye'de neresi olduğu tarafımızca bilinmektedir.

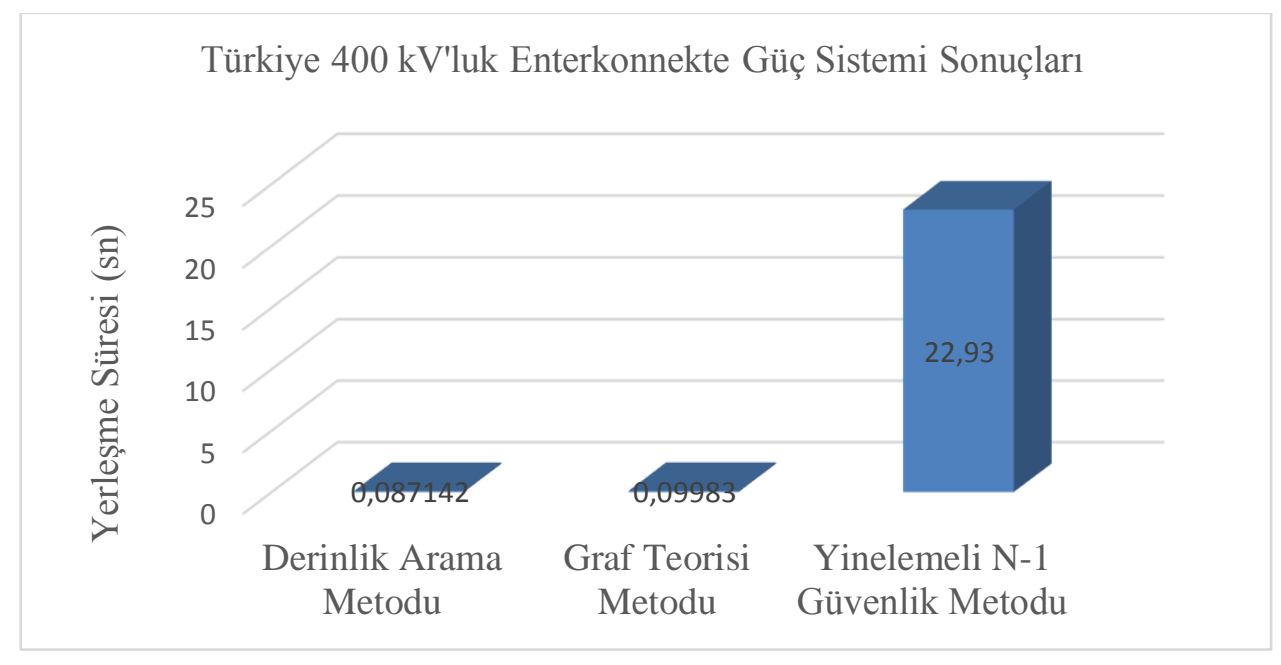

Şekil 9. Türkiye 400 kV'luk enterkonnekte güç sistemine yerleşme süre sonuçlart 
Türkiye $400 \mathrm{Kv}$ 'luk Enterkonnekte Güç Sistemi Sonuçları

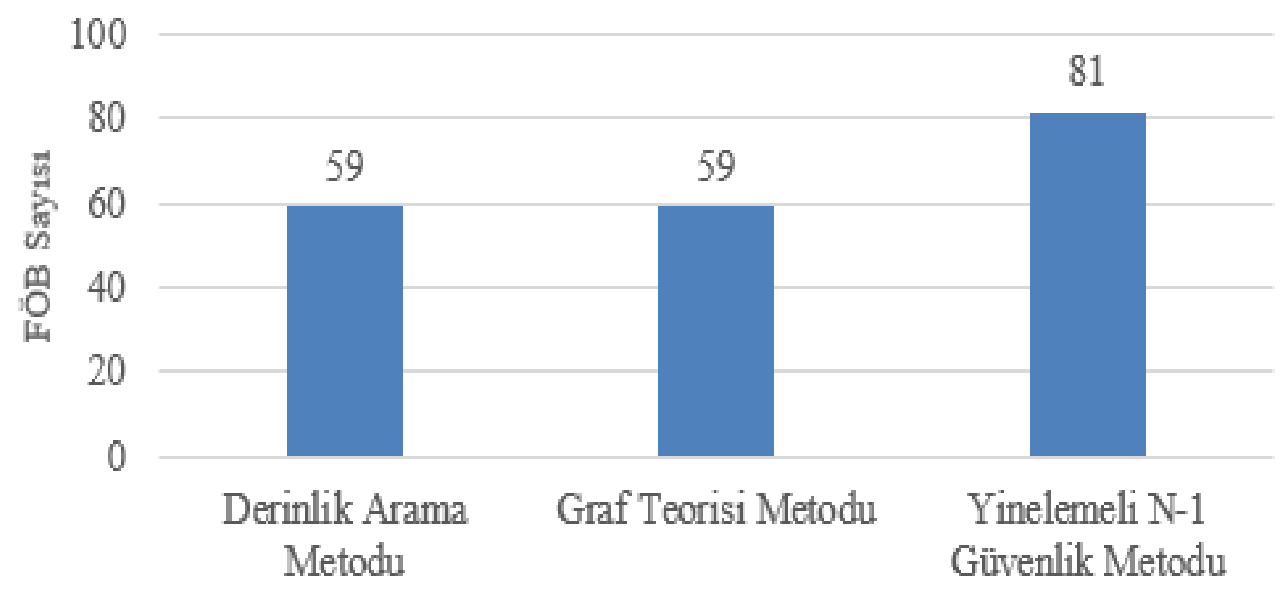

Kullanilan Metotlar

Şekil 10. Türkiye 400 kV'luk enterkonnekte güç sistemi sonuçları

FÖB cihazlarının yüksek kurulum maliyetinden dolayı sistemin tümünü gözlemlenebilir kılacak şekilde en az sayıda yerleştirilmesi istenilmektedir. FÖB optimal yerleşimi için kullanılan yöntemlerden Derinlik metodu, Graf teorisi metodu ve Yinelemeli N-1 Güvenlik metodu uygulanmıştır. FÖB'lerin şekil 10'da belirtilen sayıda ve Tablo 2'de belirtilen baralara yerleştirildiğinde sistemlerin tamamı gözlemlenebilir olmaktadır. Derinlik arama metodunda ve Graf teorisi metodu kullanıldığında 59 adet baraya FÖB yerleştirilmesi durumunda $400 \mathrm{kV}$ güç sisteminin tamamının gözlemlenebilmesi mümkündür. Yinelemeli N-1 Güvenlik metodu kullanıldığında 81 adet baraya FÖB yerleştirilmesi sonucunda $400 \mathrm{kV}$ güç sistemi gözlemlenebilmektedir. Sistemi en az sayıda FÖB ile gözlemlenebilirliği Derinlik arama metodu ve Graf teorisinde metodu ile sağlandığı görülmektedir.

\section{F. UYGULAMA 2. TÜRKIYYE $400 \mathrm{kV}$ ENTERKONNEKTE GÜÇ SISTEMİ IÇIIN PLANLANAN YENİ HATLARIN VE BARALARIN DEVREYE ALINMASI DURUMUNDA OPTIMAL FÖB YERLEŞTIRILMESI}

Türkiye $400 \mathrm{kV}$ 'luk enterkonnekte güç sistemi için planlanan yeni baralar ve iletim hatların devreye alınması durumunda güç sisteminde 167 bara ve 280 iletim hattından oluşmaktadır. (İnşası devam eden 7 bara ve 23 iletim hattı bulunmaktadır). PSAT programı ile yinelemeli N-1 Güvenlik Metodu ve Matlab programı ile Derinlik Arama Metodu, Graf Teorisi Metodu güç sistemine uygulandığında sonuçlar Tablo 3 'te verilmiştir. Enterkonnekte güç sistemini modellerken bara isimleri yerine bara numaraları kullanılmıştır.

Tablo 3. Türkiye 400 kV'luk enterkonnekte güç sistemi için planlanan yeni baralar ve iletim hatları devreyealınması durumunda FÖB yerleştirme sonuçları

\begin{tabular}{cccc}
\hline $\begin{array}{c}\text { Uygulanan } \\
\text { Yöntemler }\end{array}$ & $\begin{array}{c}\text { Geçen } \\
\text { Zaman }\end{array}$ & $\begin{array}{c}\text { Optimal Yerleştirilmesi } \\
\text { Gereken FÖB Sayısı }\end{array}$ & $\begin{array}{c}\text { Optimal FÖB Yerleştirilmesi Gereken } \\
\text { Baralar }\end{array}$ \\
\hline & & & $1,5,8,10,13,14,16,17,20,23,26,28,32$, \\
Derinlik & & \multirow{2}{*}{63} & $33,35,39,40,42,43,52,53,55,57,59,61$, \\
Arama & $0.096230 \mathrm{~s}$ & & $65,67,69,70,74,76,79,86,87,89,92,95$, \\
Metodu & & & $96,97,102,104,107,112,114,115,117,119$, \\
& & & $122,126,129,131,133,137,139,142,145$, \\
& & & $149,151,153,156,159,163,166$ \\
\hline
\end{tabular}


Tablo 3 (devam). Türkiye 400 kV'luk enterkonnekte güç sistemi için planlanan yeni baralar ve iletim hatları devreyealınması durumunda FÖB yerleştirme sonuçları

\begin{tabular}{ccl}
\hline & & $1,5,8,10,13,14,16,17,20,23,26,28,32$, \\
Graf & & $33,35,39,40,42,43,52,53,55,57,59,61$, \\
Teorisi & $0.100755 \mathrm{~s}$ & $65,67,69,70,74,76,79,86,87,89,92,95$, \\
Metodu & \multirow{2}{*}{63} & $96,97,102,104,107,112,114,115,117,119$, \\
& & $122,126,129,131,133,137,139,142,145$, \\
& & $149,151,153,156,159,163,166$ \\
\hline & & $1,4,6,7,9,11,12,15,18,19,20,24,25,26$, \\
Yinelemeli & & $27,29,31,34,36,37,38,41,44,46,47,49$, \\
N-1 & $26.9593 \mathrm{~s}$ & $51,53,55,57,59,61,65,66,67,69,70,74$, \\
Güvenlik & & $76,77,79,82,85,88,90,91,92,95,96,97$, \\
Metodu & \multirow{2}{*}{86} & $98,101,105,107,109,110,111,112,114$, \\
& & $116,119,122,123,125,126,128,129,131$, \\
& & $133,136,137,139,142,144,146,147,150$, \\
& & $151,153,155,157,159,163,164,166,167$ \\
\hline
\end{tabular}

Tablo 3'te Türkiye 400 kV'luk enterkonnekte güç sistemi için planlanan yeni baralar ve iletim hatların devreye alınması durumunda benzetim metotlarının karşılaştırılmalı sonuçları verilmektedir. Şekil 11 'de güç sistemine uygulanılan, Derinlik metodu, Graf teorisi metodu ve Yinelemeli N-1 Güvenlik metodu yerleşme süresi karşılaştırıldığında, Yinelemeli N-1 Güvenlik metodu 26.9593 sn ile güç sistemine FÖB'leri yerleştirmekte olduğu belirlenmiştir. Yinelemeli N-1 Güvenlik metodu güç sisteminde bulunan iletim hatlarını tek tek devre dışı bırakarak tüm sistemin gözlenebilmesini sağladığı için en uzun sürede sisteme FÖB'leri yerleştirmektedir. Derinlik metodu ile Graf teorisi metodu ile sisteme yerleştirilen FÖB sayıları aynı olmakla birlikte yerleşme süreleri farklıdır. Enterkonnekte güç sistemini tamamen gözlemlenebilir olması için optimal FÖB yerleştirilmesi gereken baralar Tablo 3 'te verilmektedir. Bu baralar Türkiye'de neresi olduğu tarafımızca bilinmektedir.

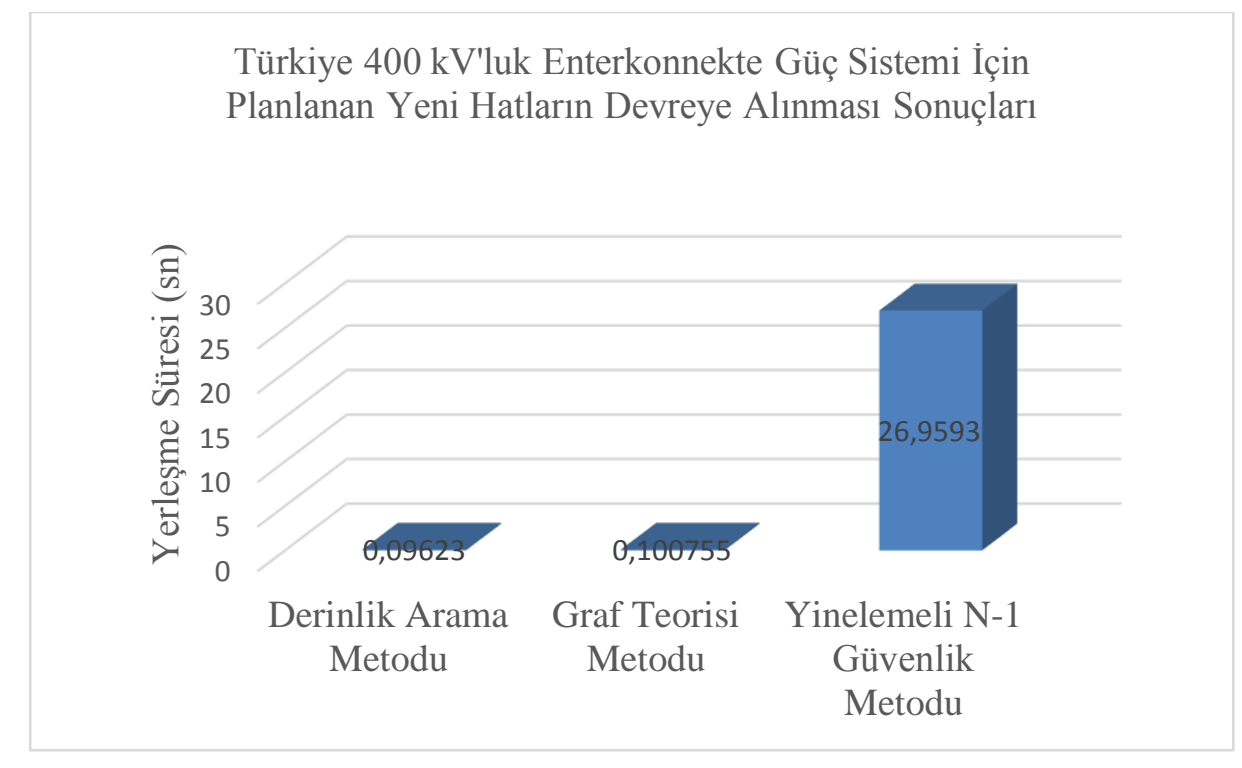

Şekil 11. Türkiye 400 kV'luk enterkonnekte güç sistemi için planlanan yeni hatların devreye alınması durumunda yerleşme süre sonuçları 
Türkiye 400 KV'luk Enterkonnekte Güç Sistemi İçin Planlanan Yeni Hatların

Devreye Alınması Sonuçları

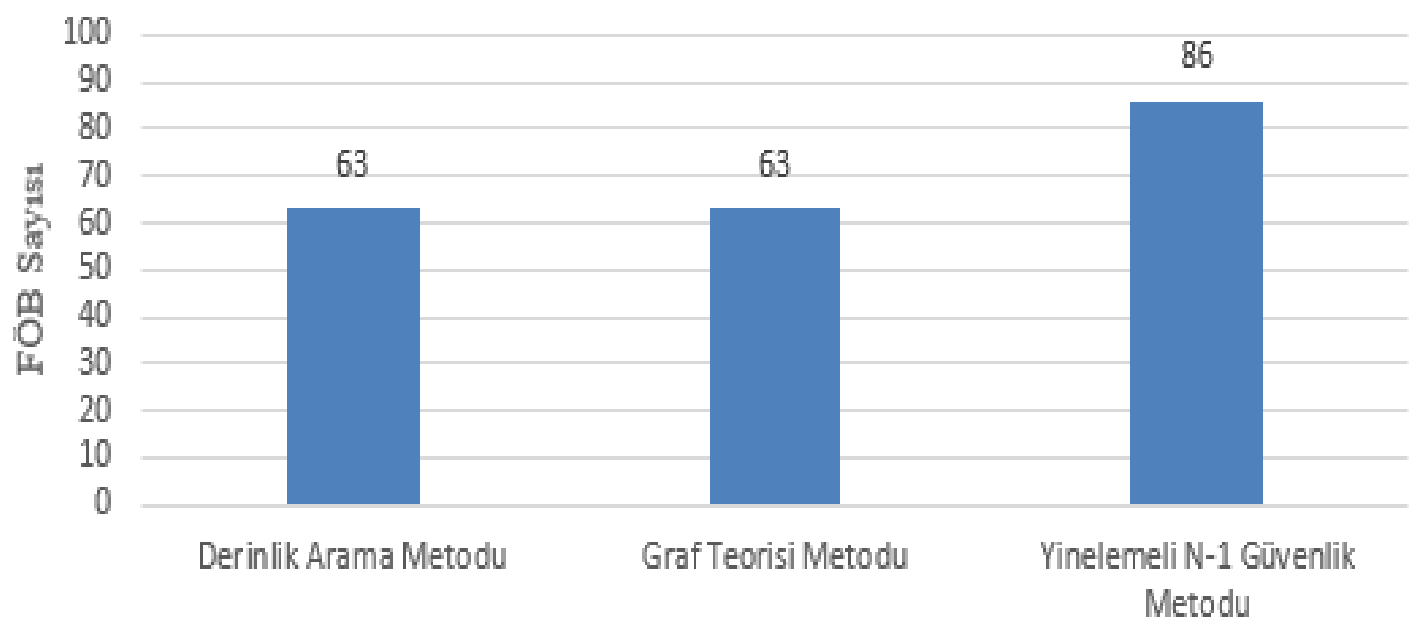

Kullanilan Metotlar

Şekil 12. Türkiye 400 kV'luk enterkonnekte güç sistemi için planlanan yeni hatların devreye alınmast sonuçları

FÖB cihazlarının kurulum maliyetlerin dolayı sistemin tümünü gözlemlenebilir kılacak şekilde en az sayıda yerleştirilmesi istenilmektedir. FÖB optimal yerleşimi için kullanılan yöntemlerden Derinlik metodu, Graf teorisi metodu ve Yinelemeli N-1 Güvenlik metodu uygulanmıştır. FÖB'lerin şekil 12'de belirtilen sayıda ve Tablo 3 'te belirtilen baralara yerleştirildiğinde sistemlerin tamamı gözlemlenebilir olmaktadır. Elde edilen sonuçlara göre Derinlik arama metodunda ve Graf teorisinde metodu kullanıldığında 63 adet baraya FÖB yerleştirilmesi durumunda $400 \mathrm{kV}$ enterkonnekte güç sisteminin tamamının gözlemlenebilmesi mümkündür. Yinelemeli N-1 Güvenlik metodu 86 adet baraya FÖB yerleştirilmesi sonucunda $400 \mathrm{kV}$ enterkonnekte güç sisteminin tamamını gözlemlenebilmektedir. Sistemi en az sayıda gözlemlenebilirliğini Derinlik arama metodu ve Graf teorisinde metodu ile gerçekleştirebiliriz.

\section{SONUC VE ÖNERILER}

Güç sistemlerinde gerilim ve açı kararsızlığı gibi olumsuz nedenlerden dolayı güç sisteminin hızlı bir şekilde tamamen gözlenebilmesi, kontrol edilmesi ve planlanması gerekmektedir. Bu çalışmada amaç fonksiyonumuz sistemin tamamını gözlemlemektir ve kısıt fonksiyonumuz ise bunu en az sayıda FÖB cihazı kullanarak yapmaktır. Bu çalışma sonucunda Türkiye 400 kV'luk enterkonnekte güç sistemi üzerinde, güç sisteminde kararsızlık anına gelmeden önce, gerekli önlemler alınarak, sistemin kararlılığı ve güvenirliği sağlanabilmesine imkân sağlamaktadır. Çalışma sonucunda hem maliyeti azaltmak hem de güç sisteminin tamamının gözlenmesinin sağlamak için optimum sayıda FÖB'leri hangi baralara yerleştirilmesi gerektiği bulunmuştur. FÖB cihazların yerleşimi ile ilgili belli baralardan ölçüm alınması gereken durumlar değerlendirilmemiştir. Örneğin; sistemin toparlanması durumunda enerjilendirilmesi düşünülen öncelikli yükler için iletim sistemin izlenmesi gerekirse, FÖB cihazları o noktalara muhakkak yerleştirilmelidir. Yapılan çalışmalara sezgisel yöntemler uygulayarak optimal FÖB sayısı ve FÖB'lerin yerleştirilmesi gereken baraları da bulabiliriz. 


\section{KAYNAKLAR}

[1] D. Chouhan and V. A. Jaiswal, "Literature Review on Optimal Placement of PMU and Voltage Stability," Indian Journal of Science and Technology, c. 9(47), 2016.

[2] A. G. Phadke and J.S. Thorp, "Synchronized Phasor Measurements and Their Applications", New York, Springer, 2008.

[3] A. G. Phadke, J. S. Thorp, and K. J. Karimi, "State Estimation with Phasor Measurements" IEEE Transactions on Power Systems, c. 1, s. 1, ss. 233-241, 1986.

[4] H. Var and B. E. Türkay, "Optimal Placement of Phasor Measurement Units for State Estimation in Smart Grid," 2016 National Conference on Electrical, Electronics and Biomedical Engineering (ELECO), Bursa, 2016, ss. 6-10.

[5] IEEE Standart for Synchro Phasors for Power Systems, C37.118-2005, IEEE, Nisan 2006.

[6] A.G. Phadke, "Phasor Measurements for Real Time Applications" IEEE Power and Energy Magazine, c. 6, s. 5, ss. 20-22, 2008.

[7] M. Shahraeini, and M.H. Javidi, "A Survey on Topological Observability of Power Systems", IEEE Power Engineering and Automation Conference PEAM, c.3, Wuhan, China, 2011.

[8] R., Saini Manju and M. Saini, "Optimal Placement of Phasor Measurement Units for Power System Observability without Considering Zero Injection Buses," International Journal of Smart Sensors and Ad Hoc Networks, c. 1, s. 4, ss. 118-122, 2012.

[9] T. L. Baldwin, L. Mili, M. B. Boisen. and R. Adapa, "Power System Observability with Minimal Phasor Measurement Placement,” IEEE Trans. Power Syst., c. 8, s. 2, ss. 701-715, 1993.

[10] B.M. Ivatloo, "Optimal Placement of PMUs for Power System Observability Using Topology Based Formulated Algorithms,” Journal of Applied Sciences, c. 9, s. 13, ss. 2463- 2468, 2009.

[11] P. Jiangnan, S. Yuanzhang and H. F. Wang, "Optimal PMU Placement for Full Network Observability using Tabu Search Algorithm," Electrical Power and Energy Systems, c. 28, s. 4, ss. 223-231, 2006.

[12] A. Y. Abdelaziz, Amr M. Ibrahim, and Reham H. Salem, "Power System Observability with Minimal Phasor Measurement Units Placement," International J. Eng. Sci. Technol., c. 5, s. 3, ss. $1-18,2013$.

[13] T.-T. Cai and Q. Ai., "Research of PMU Optimal Placement in Power Systems," 2005 World Sci. Eng. Acad. Soc. Int. Conf, ss. 38-43, 2005.

[14] H. Goklani, N. A. Chauhan, M. Prajati, "Optimal Placement of Phasor Measurement Unit in Smartgrid," International Conference on Advance Trends in Engineering and Technology (ICATET-2014), Jaipur, Rajsthan, c. 2, 2014.

[15] R. F. Nuqui ve A. G. Phadke, "Phasor Measurement Unit Placement Techniques for Complete and Incomplete Observability," IEEE Transactions on Power Delivery, c. 20(4), s. 2381-2388, 2005.

[16] B. Milosevic ve M. Begovic, "Nondominated Sorting Genetic Algorithm for Optimal Phasor Measurement Placement," IEEE Transactions on Power Systems, c. 18(1), ss. 69-75, 2003.

[17] Y. Gao, Z. Hu, X. He and D. Liu, “Optimal Placement of PMUs in Power Systems Based on 
Improved PSO Algorithm," 2008 3rd IEEE Conference on Industrial Electronics and Applications, ss. 2464-2469, 2008.

[18] D. Devesh, D. Sanjay, K. G. Rajeev and S. A. Soman, "Optimal Multistage Scheduling of PMU Placement: An ILP Approach,” IEEE Trans. Power Delivery, c. 23, s. 4, ss. 1812- 1820, 2008.

[19] Singh et al., "Applications of Phasor Measurement Units (PMUs) in Electric Power System Networks Incorporated with FACTS Controllers”, International Journal of Engineering, Science and Technology, c. 3, s. 3, ss. 64-82, 2011.

[20] M.A.M. İpek, "Elektrik Güç Sistemlerinde Geniş Alan Ölçüm Sistemi ve Fazör Ölçüm Birimi Yerleşiminin İncelemesi”, Yüksek Lisans Tezi, ITÜ̈ Fen Bilimleri Enstitüsü, İstanbul, Türkiye, ss. 5-20, c. $53,2008$.

[21] A. Sarıtaş, "Akı1lı Şebekeler Ve Fazör Ölçüm Birimlerinin Şebekeye Optimal Yerleşimi," Yüksek Lisans Tezi, Gazi Üniversitesi Fen Bilimleri Enstitüsü, Ankara, 2013.

[22] M. Varan, S. Haidary, İ. ÖYLEK ve Ö. CANAY, “Akılll Şebekelerde Güvenli Haberleşme Tabanlı Güç Akışı Analizi," Journal of New Results in Engineering and Natural Science, No:8 pp. 68, 2018.

[23] Z. Sha, Y. Hao, Y. Hao ve diğerleri, "A New Algorithm for PMU Placement Optimization in Power System,” s. 4(7), ss. 31-36, 2005.

[24] P. Xu and B. F. Wollenberg, "Power System Observability and Optimal Phasor Measurement Unit Placement," ss. 1-34, 2015.

[25] F. Milano, "Power System Analysis Toolbox Documentation for PSAT," version 2.0.0, Şubat 14, ss. 89-98, 2008.

[26] B. Xu, and A. Abur, "Observability Analysis and Measurement Placement for System with PMUs,” Proc. IEEE Power System Conf. Expo, s. 2, ss. 943-946, 2004.

[27] D. Dua, S. Dambhare R.K. Gajbhiye, and S.A. "Soman, Optimal Multistage Scheduling of PMU Placement: An ILP Approach,” IEEE Trans. Power Del., s. 23, ss. 1812-1820, 2008.

[28] D. Narsingh, "Graph Theory with Applications to Engineering and Computer Science," Prentice Hall Inc, 1974.

[29] S. Chakrabarti, E. Kyriakides, and D.G. Eliades, "Placement of Synchronized Measurements for Power System Observability," IEEE Trans. Power Deliv., s. 24, ss. 12-19, 2009.

[30] B. Xu and A. Abur, "Optimal Placement of Phasor Measurement Units for State Estimation, Final Project Report," PSERC, 2005.

[31] P. T. Nikolaos, M. M. Nikolaos, N. K. George, "Optimal PMU Placement Using Nonlinear Programming," 1st International Conference on Engineering and Applied Sciences Optimization, ss. 240-258, 2014.

[32] M.M. Begovic, and A.G. Phadke, "Voltage Stability Assessment through Measurement of a Reduced State Vector", IEEE Transactions on Power Systems, PWRS-5(1), ss. 198-203, 1990.

[33] M.M. Begovic, "Analysis Monitoring and Control of Voltaae Stability in Electric Power Systems”, Doktora Tezi, Virginia Polytechnic Institute and State University, Temmuz, 1989. 
[34] The University of New South Wales, "Power System Analysis Toolbox Documentation for PSAT version 1.3.4," [Çevrimiçi]. http://seit.unsw.adfa.edu.au/staff/sites/hrp/research/PSAT/psat-1.3.4.pdf. Erişim Tarihi:07.10.2019

[35] S. Russell and P. Norvig, “Articial Intelligence: A Modern Approach,” 2009.

[36] G. B. Denegri, M. Invernizzi and F. Milano "A Security Oriented Approach to PMU Positioning for Advanced Monitoring of a Transmission Grid," in Proc. of PowerCon 2002, Kunming, China, Kasim, 2002.

[37] Türkiye Elektrik İletim Anonim Şirketi (TEİA), Araştırma ve Geliştirme (AR-GE) Müdürlüğü. 